\title{
Cell Lineage Analysis Reveals Three Different Progenitor Pools for Neurosensory Elements in the Otic Vesicle
}

\author{
Dora Sapède, ${ }^{\star}$ Sylvia Dyballa, ${ }^{\star}$ and Cristina Pujades \\ Department of Experimental and Health Sciences, Universitat Pompeu Fabra, Barcelona Biomedical Research Park, 08003 Barcelona, Spain
}

In the inner ear, sensory versus neuronal specification is achieved through few well-defined bHLH transcription factors. However, the molecular mechanisms regulating the generation of the appropriate cell type in the correct place and at the correct time are not completely understood yet. Various studies have shown that hair cell- and neuron-specifying genes partially overlap in the otic territory, suggesting that mutual interactions among these bHLH factors could direct the generation of the two cell types from a common neurosensory progenitor. Although there is little evidence for a clonal relationship between macular hair cells and sensory neurons, the existence of a single progenitor able to give both sensory and neuronal cell types remains an open question. Here, we identified a population of common neurosensory progenitors in the zebrafish inner ear and studied the proneural requirement for cell fate decision within this population. Expression analysis reveals that proneural genes for hair cells and neurons overlap within the posteromedial otic epithelium. Combined results from single-cell lineage and functional studies on neurog1 and neuroD1 further demonstrate the following: (1) in the anterior region of the ear, neuronal and sensory lineages have already segregated at the onset of proneural gene expression and are committed to a given fate very early; (2) in contrast, the posteromedial part of the ear harbors a population of common progenitors giving both neurons and hair cells until late stages; and finally (3) neuroD1 is required within this pool of bipotent progenitors to generate the hair cell fate.

\section{Introduction}

In vertebrates, two key cell types underlie the function of mechanosensory systems: the hair cells that transduce the mechanical stimuli and the sensory afferent neurons that conduct the extracted information to the brainstem. In mammals, these neurosensory cells have a limited regeneration capacity, and their lifespan is truncated by numerous environmental conditions and a genetic predisposition, leading to an increase of agedependent progressive hearing loss (Corwin and Cotanche, 1988; Bermingham-McDonogh and Rubel, 2003). Thus, to ultimately provide replacement of lost neurosensory cells, it is

Received Aug. 1, 2012; revised Sept. 12, 2012; accepted Sept. 18, 2012.

Author contributions: D.S., S.D., and C.P. designed research; D.S., S.D., and C.P. performed research; D.S., S.D., and C.P. analyzed data; D.S. and C.P. wrote the paper.

*D.S. and S.D. contributed equally to this work.

The work was funded by Ministry of Science and Innovation Grant BFU2009-07010 (C.P.). D.S. was a recipient of a postdoctoral Juan de la Cierva contract (Ministry of Science and Innovation) and S.D. of a predoctoral FI fellowship (Agency for Management of University and Research Grants, Government of Catalonia). We are grateful to M. Linares for technical assistance, J. Sharpe for critical reading of this manuscript, and the members of the Developmental Biology Group for insightful comments. We thank those who kindly provided us transgenic fish lines and reagents, especially P. Blader for the neurog $7^{\text {hi1059 }}$ fish line and pCS2-nrd construct, M. Hibi for the anti-neuroD1 antibody, V. Lecaudey for the $\operatorname{tg}[\mathrm{cldnb}$ :lynGFP] line, N. Peyrieras for the H2B-mcherry vector, and D. Raible for the sox 10:nls-eos construct.

The authors declare no competing financial interests.

Correspondence should be addressed to Dr. Cristina Pujades, Department of Experimental and Health Sciences, Universitat Pompeu Fabra, Barcelona Biomedical Research Park, Dr. Aiguader 88, 08003 Barcelona, Spain. E-mail: cristina.pujades@upf.edu.

D. Sapède's present address: Joint Research Unit 5547, National Center for Scientific Research, Center of Developmental Biology, Paul Sabatier University, 31062 Toulouse, France.

DOI:10.1523/JNEUROSCI.3686-12.2012

Copyright $\odot 2012$ the authors $\quad 0270-6474 / 12 / 3216424-12 \$ 15.00 / 0$ essential to unveil the mechanisms for determining the fate of these cell types from early progenitors.

All the cellular components of the inner ear, afferent neurons and both sensory and nonsensory epithelia, arise from the otic placode, a simple ectodermal thickening adjacent to the hindbrain. This requires a tight coordination between morphogenesis and cell fate specification. The molecular basis of neurosensory development has been studied extensively, and it depends on the function of three proneural genes: atoh 1 for hair cell formation (Bermingham et al., 1999; Millimaki et al., 2007), neurog1 for sensory neuron determination (Ma et al., 1998; Andermann et al., 2002), and neuroD1 for sensory neuron differentiation and survival (Kim et al., 2001; Jahan et al., 2010a).

In zebrafish, neurogenesis and hair cell specification take place simultaneously (Haddon and Lewis, 1996). The neurogenic region partially overlaps with the sites in which sensory patches will develop (Haddon et al., 1998; Andermann et al., 2002; Millimaki et al., 2007; Sapède and Pujades, 2010), raising the question of whether neurons and hair cells arise from a common progenitor cell. Clonal analysis in chick showed that neurons of the cochleo-vestibular ganglion can be related to utricular epithelial cells (Satoh and Fekete, 2005), although the lack of genetic tools did not allow precise localization of the original targeted cell. In mouse, part of the vestibular hair cells of the maculae derive from the neurogenic domain, although the clonal descendance from a common progenitor still remains to be demonstrated (Raft et al., 2007). In line with this, it had been proposed that the neurosensory precursors may be composed of three populations: (1) neuronal precursors that form only neurons, (2) sensory precursors 
that form only hair cells, and (3) precursors that give rise to both cell types (Fritzsch et al., 2006).

In this work, we identify a common neurosensory precursor population and describe neuroD1 as a key proneural gene for hair cell specification within this population. Expression analysis reveals that proneural genes for neurons and for hair cells partially overlap within the posteromedial otic epithelium. Cell tracing experiments demonstrate that precursors of sensory neurons and hair cells in the anterior otic vesicle are already committed to alternative fates at the onset of proneural gene expression; meanwhile, the posterior epithelium still contains a cell population with dual potential. Functional experiments with neurog1 and neuroD1 demonstrate the following: (1) the precursors for neurons and hair cells are segregated in the anterior macula; (2) a subpopulation of neuronal progenitors in the posteromedial territory can switch the fate to hair cells; and (3) neuroD1 is required for the bipotent progenitors to generate hair cells.

\section{Materials and Methods}

\section{Zebrafish strains and maintenance}

Zebrafish embryos (Danio rerio) were obtained by pair mating of adult fish by standard methods in the Barcelona Biomedical Research Park zebrafish facility. All fish strains were maintained individually as inbred lines. The $\operatorname{tg}[\mathrm{Brn} 3 \mathrm{c}: \mathrm{mGFP}]$ line expresses GFP in the hair cells of the ear and lateral line system (Xiao et al., 2005). In tg[Isl3:GFP] (Islet3 also called Isl2b), GFP is expressed in the afferent sensory neurons of the ear and lateral line system and in facial and trigeminal ganglia (Pittman et al., 2008). The previously described tg[cldnb:lynGFP] line (Haas and Gilmour, 2006) was mainly used in this study as a plasma membrane marker in otic structures. Embryos homozygous for the neurog ${ }^{\text {hilos9 }}$ mutation (Golling et al., 2002; called neurog $1^{-1}$ in this article) were obtained by incross of heterozygous carriers; the presence of the neurog $1^{\text {hilos9 }}$ allele was identified by PCR genotyping of tail fin-clips or embryonic tails genomic DNA. All procedures used have been approved by the institutional animal care and use ethic committee (Barcelona Biomedical Research Park Institutional Animal Care and Use Committee) and implemented according to national rules and European regulations.

\section{Antisense morpholinos and missexpression constructs}

For morpholino knockdowns, embryos were injected at the 1-cell stage with translation-blocking morpholino oligomers (MOs) obtained from GeneTools. MO injections were as follows: $5 \mathrm{ng}$ of neurog $1-\mathrm{MO}, 5^{\prime}$-ACG ATC TCC ATT GTT GAT AAC CTG G-3' (Cornell and Eisen, 2002); 16 ng of neuroD1-MO, 5'-TGA CTT CGT CAT GTC GGA ACT CTA G-3' (Sarrazin et al., 2006); and $7.5 \mathrm{ng}$ of p53-MO, 5'-GCG CCA TTG CTT TGC AAG AAT TG-3' (Langheinrich et al., 2002).

For rescue experiments, the number of hair cells in the anterior macula (AM) and posterior macula (PM) was quantified, and the AM/PM ratio was calculated to minimize the heterogeneity in hair cell numbers attributable to (1) a possible slight embryonic developmental delay of $\operatorname{tg}[$ Brn3c:mGFP $]$ neurog1 ${ }^{-/-}$embryos injected with MO-neuroD1/MO$\mathrm{p} 53$, and (2) the variability in penetrance of MO-neuroD1 within the injected embryo population, as characterized previously (Sarrazin et al., 2006).

For ectopic mRNA expression, neuroD1 construct pCS2-nrd was used (Blader et al., 1997) and coinjected with H2B-mcherry mRNA (Olivier et al., 2010). Embryos at the 1-cell or 16-cell stage were injected with $90 \mathrm{pg}$ of mRNA and left to develop at $28^{\circ} \mathrm{C}$ until desired stages.

\section{In situ hybridization and immunolabeling}

Whole-mount in situ hybridization was performed as described previously (Hauptmann and Gerster, 1994). Double in situ hybridization was performed according to the method of Brend and Holley (2009) with some modifications. In the double fluorescence in situ hybridization, fluorescein (FLUO)- and digoxigenin-labeled probes were detected with Tyramide Signal Amplification fluorescein and Fast Red, respectively. In the case of chromogenic in situ hybridization, labeled probes were detected with Fast Red and NBT/BCIP substrate. Probes were as follows: atoh1a (Millimaki et al., 2007), neurog1 and neuroD1 (Itoh and Chitnis, 2001), and neuroD4 (Park et al., 2003).

For immunolabeling, staged embryos were fixed in $4 \%$ paraformaldehyde (PFA) overnight at $4^{\circ} \mathrm{C}$ and washed in PBST (0.1\% Tween 20/PBS). Embryos were permeabilized with $10 \mu \mathrm{g} / \mathrm{ml}$ Proteinase K (Invitrogen) at room temperature for $10-30 \mathrm{~min}$, fixed for $20 \mathrm{~min}$ in $4 \%$ PFA, and incubated overnight at $4^{\circ} \mathrm{C}$ with primary antibodies in blocking solution. Primary antibodies were polyclonal antibody (pAb) anti-neuroD1 (Kani et al., 2010), pAb anti-GFP (1:400; Clontech), and pAb anti-DsRed (1: 1000; Clontech). For anti-neuroD1, immunolabeling was done on sections, and antigen retrieval was performed by boiling the sections in 10 $\mathrm{mm}$ citric acid at $95^{\circ} \mathrm{C}$ for $1 \mathrm{~h}$. After extensive washings with PBST, embryos were incubated with secondary antibodies conjugated with $\mathrm{Al}$ exa Fluor 488 (green) or Alexa Fluor 549 (red) (1:400; Invitrogen) in blocking solution at room temperature for $3 \mathrm{~h}$. After PBS washings, whole-mount embryos and sections were imaged under a fluorescence microscope (Leica DM6000B).

\section{Cryostat and vibratome sectioning}

Embryos were fixed in 4\% PFA, cryoprotected in 15\% sucrose, and embedded in $7.5 \%$ gelatin $/ 15 \%$ sucrose. Blocks were frozen in 2-methylbutane (Sigma) to improve tissue preservation, and then $20 \mu \mathrm{m}$ sections were cut on a Leica CM 1510-1 cryostat. For vibratome sections, fixed embryos were embedded in $4 \%$ low-melting-point (LMP) agarose before sectioning in a Leica VT1000S vibratome. Transverse sections were $25 \mu \mathrm{m}$ thick.

\section{Cell counting}

Hair cell counts were performed in tg[Brn3c:mGFP] embryos. We compiled results from several independent experiments in which we counted the numbers of GFP-positive cells in whole-mount living or fixed embryos [48 hours postfertilization (hpf), $56 \mathrm{hpf}, 3$ days postfertilization (dpf)]. The values obtained from cell counts were plotted, and corresponding statistical $p$ values were determined.

\section{Cell tracing experiments}

Tracing of neurog1-positive cells. To follow the fate of neurog1-positive cells, we took advantage of the enhanced expression of neurog 1 in neurog1-morphants (Jeong et al., 2006), attributable to either a negative autoregulation of neurog1 (Raft et al., 2007) or a higher stability of neurog1 mRNA when neurog1 translation is blocked. $\operatorname{tg}[\mathrm{Brn} 3 \mathrm{c}: \mathrm{mGFP}] \mathrm{em}-$ bryos were injected with MO-neurog1, and cells expressing neurog1 mRNA were monitored at later stages by in situ hybridization (even at the stage when otic epithelial cells would have switched off neurog1 expression). Control or MO-neurog1-injected embryos were hybridized with a FLUO-neurog1 probe detected with Fast Red, followed by anti-GFP staining to reveal the differentiated hair cells of the AM and PM.

Lineage tracing of otic progenitors by EosFP photoconversion. nls-eos was excised from the sox10:nls-eos original construct (Curran et al., 2010) and cloned into a pCS2 vector. Capped mRNA from pCS2-nls-eos was synthetized using SP6 kit (Ambion) and injected in 8- to 32-cell-stage embryos. $n l s-$ eos mRNA injections were performed in embryos resulting from crosses between $\operatorname{tg}[\mathrm{Brn} 3 \mathrm{c}: \mathrm{mGFP}]$ or $\operatorname{tg}[\mathrm{Isl} 3: \mathrm{GFP}]$ lines and $\operatorname{tg}[\mathrm{cld}-$ nb:lynGFP] to obtain GFP signal in the plasma membrane and photoconvertible green Eos (EosG) in the nucleus. At 16 hpf, embryos were dechorionated, anesthetized with tricaine, and screened for the presence of EosG-positive cells in the otic region. Selected embryos were then mounted dorsally or dorsolaterally in 1\% LMP-agarose. For each ear, a single cell in the otic epithelium was photoconverted with UV light $(\lambda=$ $405 \mathrm{~nm}$ ) using a $20 \times$ objective in a Leica SP5 system. During exposure of UV light, Eos protein irreversibly shifts emission from green to red fluorescence ( 516 to $581 \mathrm{~nm}$ ) (EosR). Photoconversion was assessed by acquisition of a $z$-stack of the otic region. To ensure that only a single cell was hit and that the derivatives were precisely located and identified, we did an accurate analysis using the $y z$ confocal cross-sections at the confocal plane at which the signal was observed. Photoconverted zebrafish embryos were returned to embryo medium with phenylthiourea in a $28.5^{\circ} \mathrm{C}$ incubator. At $48 \mathrm{hpf}$, embryos were mounted dorsally and imaged in vivo on a Leica TCS SP5 II CW-STED (without stimulated emission depletion) system using hybrid detectors and a $10 \times$ objective. Cell fate 
was assessed by position and morphology of the EosR cells and by overlapping with GFP expression from the transgenic lines Brn3c:mGFP (hair cells) and Isl3:GFP (neurons).

\section{Imaging and image processing}

Embryos were anesthetized in tricaine and mounted on glass-bottomed Petri dishes (Mattek) in 1\% LMP-agarose. Imaging was performed on a Leica SP5 confocal microscope using $20 \times, 40 \times$, and $63 \times$ objectives. Usually, for $y z$ confocal cross-sections, $z$-stacks were acquired with a 1-2 $\mu \mathrm{m} z$ distance. Image processing and analysis were done with FIJI (NIH ImageJ 1.46j).

\section{Results}

Neurogenesis and hair cell production coincide in a restricted domain of the posterior otic epithelium

In zebrafish, hair cells of the utricular and saccular maculae and innervating stato-acoustic ganglia (SAG) sensory neurons are produced within the first $48 \mathrm{~h}$ of life. The simultaneous generation of the two major sensory cell types prompted us to address how neurogenesis and hair cell production are spatially and temporally integrated during otic development.

neurog1 is necessary to induce otic sensory neurons (Ma et al., 1998), whereas atoh1 gene function is required for hair cell production in the maculae (Millimaki et al., 2007). The expression of neurog1 starts at 16-18 hpf in the anterior and ventral aspect of the otic vesicle (Andermann et al., 2002; Radosevic et al., 2011), and it labels only transiently the proliferating otic epithelial neuroblasts. Another bHLH factor involved in neurogenesis, neuroD1, is then activated downstream of neurog1 in the otic epithelium, and its expression is maintained through differentiation and maturation of otic neurons (Ma et al., 1998; Andermann et al., 2002). Otic neuron production peaks at 22-30 hpf (Haddon and Lewis, 1996), which corresponds to the period of activation of atoh1a in macular rudiments (Millimaki et al., 2007). We showed in a previous study that atoh1a expression is asynchronously activated, first in the AM at 22-25 hpf and then at 27-30 hpf in the posteromedial domain of the otic vesicle in which the PM will develop (Sapède and Pujades, 2010).

To explore whether expression domains of proneural genes for neurons and hair cells overlap in otic territories, we performed double RNA in situ hybridizations for neuroD1 and atohla at different stages of macular development (24-48 hpf; Fig. 1).

At $24 \mathrm{hpf}$, when atoh1a is only expressed in the AM, confocal analysis of fluorescent double staining showed that cells expressing neuroD1 and atohla in the anterior part of the ear were located at different dorsoventral levels (Fig. $1 A-C$ ): neuroD1positive cells were located mainly within the SAG, although few of them could be detected in the ventral aspect of the otic epithelium (Fig. 1A), whereas atoh1a-expressing cells were detected in more dorsal positions (Fig. $1 B, C$ ). The same analysis performed at 28 hpf, at the onset of atohla expression in the PM, showed that atoh1a and neuroD1 expression domains were now clearly segregated at the level of the developing anterior sensory macula, with neuroD1 being restricted to the SAG and atohla to the sensory epithelium (Fig. 1D,G). However, in the developing PM, the more posterior part of neuroD1 expression domain overlapped with atoh1a-expressing cells (Fig. 1 E, H, inserts in F, I). By 48 hpf, proneural genes for neurons and hair cells were expressed in different cell populations, with neuroD1 being restricted to the SAG and atohla to the epithelium of the AM and PM (Fig. $1 J-L$ ).

Although the resolution of in situ hybridization experiments is not sufficient to demonstrate the possible coexpression of these proneural genes in the very same cell, these results show that atoh1a and neuroD1 are expressed in adjacent epithelial cells of the future PM in which hair cell and neuron production overlap spatially and temporally.

\section{A subpopulation of neuronal progenitors switches to hair cell fate in the absence of neurog1 function}

Our gene expression studies suggested that a subset of sensory neurons and hair cells of the PM could derive from a common field of neurog1 progenitors. We thus reasoned that these progenitors might be forced to adopt the hair cell fate in the absence of neurog1 function.

To test this hypothesis, we assessed the production of hair cells by using Brn3c:mGFP transgenic embryos injected with $\mathrm{MO}$ neurog1 (Fig. 2). The knockdown of neurog1 resulted in the previously described loss of cranial ganglia, including the otic sensory neurons (data not shown; Andermann et al., 2002). This phenotype was accompanied by specific effects on hair cell production in the PM, which appeared larger (Fig. 2A-D) and displayed a robust increase in the number of hair cells (Fig. 2I; control, $12.2 \pm 2.8$ cells, $n=9$; MO-neurog $1,18.9 \pm 3$ cells, $n=$ $10 ; p<0.005)$ compared with control embryos. The PM phenotype was maintained at least until $3 \mathrm{dpf}$ (Fig. 2I; control, $35.9 \pm$ 3.3 cells, $n=13$; MO-neurog1, $44 \pm 4.1$ cells, $n=14$; $p<0.005$ ). The PM lies in the posteromedial otic wall and develops a complex shape, with a large and round posterior part and an elongated anterior extension (Haddon and Lewis, 1996). In the embryos injected with MO-neurog1, expansion of hair cells was consistently restricted to the anterior part of the PM (ant-PM) (see comparative color bars in Fig. 2C,D). This was confirmed when hair cells were quantified separately in the ant-PM and the posterior part of the PM (post-PM) at $48 \mathrm{hpf}$ (Fig. 2J; ant-PM: control, $14 \pm 1.15$ cells, $n=13$; MO-neurog1, $20.5 \pm 3.6$ cells, $n=14 ; p<0.005$; post-PM: control, $22.9 \pm 1.3$ cells, $n=13$; MO-neurog1, $22.93 \pm 2.5$ cells, $n=14$ ), suggesting that supernumerary hair cells arise from the region of the otic epithelium in which the prosensory field and the neurogenic domain overlap. In contrast, no changes in the number of hair cells in the AM were observed when neurog1 function was blocked (Fig. 2A,B,I; 48 hpf: control, $12.3 \pm 1.7$ cells, $n=12$; MO-neurog $1,12.8 \pm 1.9$ cells, $n=9$; 3 dpf: control, $33 \pm 2$ cells, $n=12$; MO-neurog 1 , $35.9 \pm 2.2$ cells, $n=13$ ). The morphants did not display any defect in the development of hair cells of the cristae (Fig. 2E,F), which are generated later than maculae.

To further confirm this phenotype, we performed a similar analysis using the neurog $1^{1059}$ mutants (Golling et al., 2002). We generated a neurog $1^{+/-}$fish line in the $\operatorname{tg}[\mathrm{Brn} 3 \mathrm{c}: \mathrm{mGFP}]$ background, which allowed us to use the same readout for hair cells as used in the analysis of the morphants. The neurog $1^{-/-}$mutants displayed an increased number of hair cells specifically in the PM [Fig. 2G, H, K; AM: wild type (WT), $29.6 \pm 2.2$ cells, $n=12$; neurog $1^{-/-}$, $30.6 \pm 3.6$ cells, $n=13$; PM: WT, $30.3 \pm 3.7$ cells, $n=12$; neurog $1^{-/-}, 42 \pm 5$ cells, $\left.n=13 ; p<0.001\right]$, similar to what was observed in the morphants.

In summary, we showed that in the absence of neurog 1 function, otic sensory neurons do not form while an excess of hair cells is produced in the anterior region of the PM. These results suggest that a subset of otic neuronal progenitors have differentiated into hair cells.

Next, we examined whether atoh1a expression was modified during neurog1 inhibition. After the normal delay in atoh1a expression between the AM and PM, hair cell differentiation starts at $\sim 30 \mathrm{hpf}$ in the AM and at $36 \mathrm{hpf}$ in the PM (Fig. 3 A, C; Sapède and Pujades, 2010). We observed that, at $34 \mathrm{hpf}$, the PM of con- 

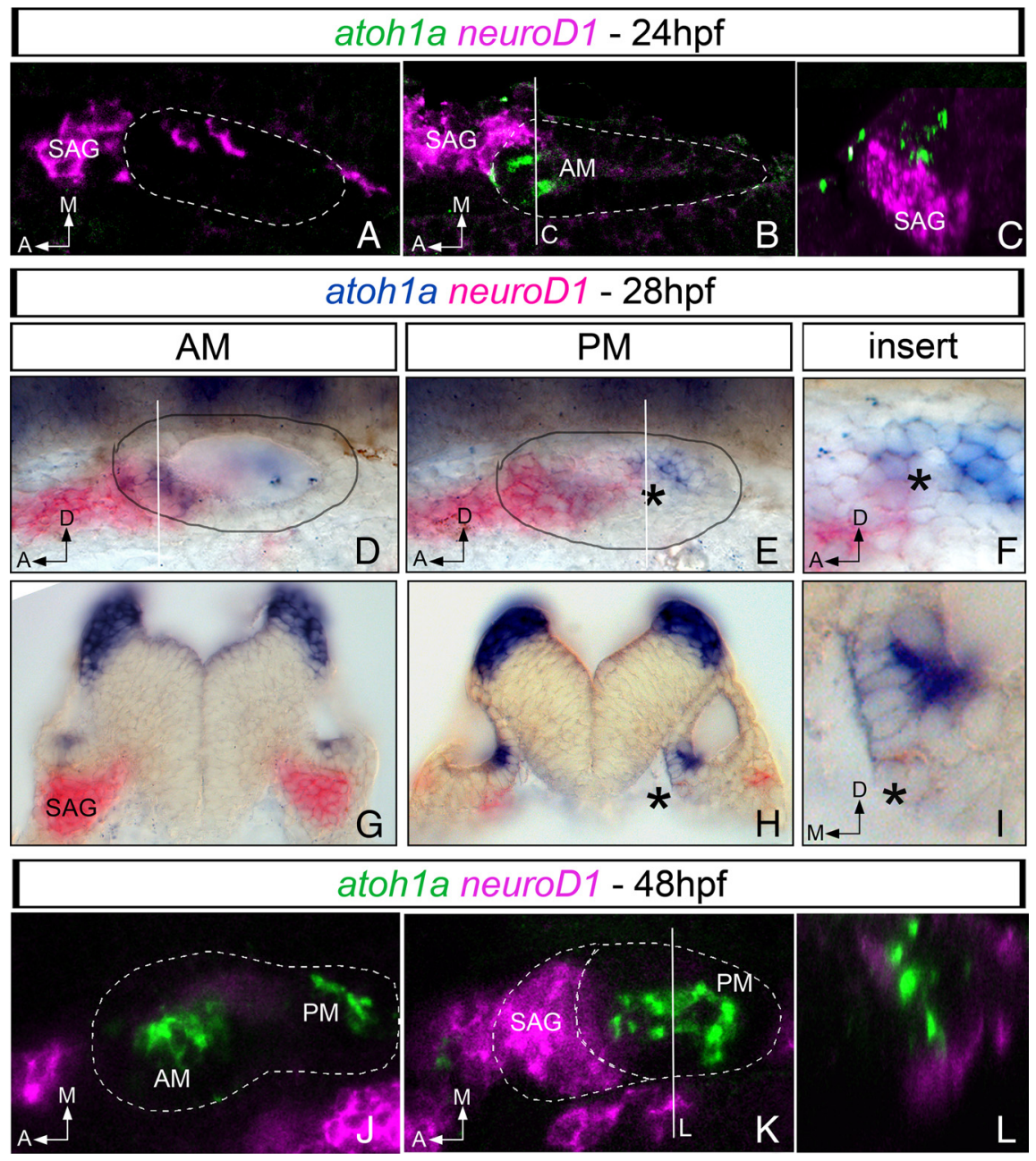

Figure 1. Expression of proneural genes for neurons and hair cells overlaps in the posteromedial domain of the otic vesicle. Whole-mount fluorescent $(\boldsymbol{A}-\boldsymbol{C}, \boldsymbol{J}-\boldsymbol{L})$ or chromogenic $(\boldsymbol{D}-\boldsymbol{I})$ double in situ hybridization for atoh1a (green/blue) and neuroD1 (magenta/pink) in $24 \mathrm{hpf}(\boldsymbol{A}-\boldsymbol{C}), 28 \mathrm{hpf}(\boldsymbol{D}-\boldsymbol{I})$, and $48 \mathrm{hpf}(\boldsymbol{J}-\boldsymbol{L})$ zebrafish embryos. neuroD1 and atoh1a display non-overlapping regions of expression in the anterior aspect of the otic vesicle at $24 \mathrm{hpf}: \boldsymbol{A}$, ventral confocal plane showing expression of neuroD1 in the most ventral aspect of the otic epithelium and in the $S A G ; \boldsymbol{B}$, more dorsal confocal plane showing expression of neuroD1 in the SAG and atoh $1 a$ in the otic epithelium; and $\boldsymbol{C}, y z$ confocal cross-section of $\boldsymbol{B}$ (white line) showing that neuroD1 and atoh $1 a$ are indeed expressed in neighboring cells. In $28 \mathrm{hpf}$ embryos ( $\boldsymbol{D}-\boldsymbol{I})$, neuroD1 and atoh1a display exclusive regions of expression in the anterior aspect of the otic vesicle and in the $\operatorname{SAG}(\boldsymbol{D}$, transverse section in $\boldsymbol{G})$. Note the overlapping domain of gene expression in the posteromedial domain of the otic epithelium (black asterisk in $\boldsymbol{E}$ and in the corresponding transverse section in $\boldsymbol{H}$ ). $\boldsymbol{F}$ and $\boldsymbol{I}$ are inserts of $\boldsymbol{E}$ and $\boldsymbol{H}$, respectively. At $48 \mathrm{hpf}(\boldsymbol{J}-\boldsymbol{L})$, neuroD1 expression is mainly restricted to the SAG and atoh1a to the AM and PM $(\boldsymbol{J}, \boldsymbol{K}) . \boldsymbol{L}$, yz confocal cross-section of $\boldsymbol{K}$ (white line) showing that atoh1a and neuroD1 expression does not overlap. White dotted lines and black circles indicate the contour of the otic vesicle. Dorsal $(\boldsymbol{A}, \boldsymbol{B}$ and $\boldsymbol{J}, \boldsymbol{K})$, and lateral views $(\boldsymbol{D}-\boldsymbol{F})$ with anterior to the left. G-I, Transverse sections. A, Anterior; D, dorsal; M, medial.

trol embryos contained only the two tether cells, whereas in the PM of neurog1 morphants, there were already more than two hair cells at the same stage (Fig. $3 B, D$ ). Consistent with this premature differentiation of PM hair cells, atohla was precociously upregulated at $25 \mathrm{hpf}$ in the posteromedial domain of the otic epithelium in the morphants (Fig. $3 E, F$ ). No differences in the number of tether cells (Fig. $3 A, B$ ) or in the expression of atoh $1 b$ (data not shown) were observed. In neurog $1^{-/-}$embryos, the atohla domain was enlarged in the PM (Fig. $3 G, H$, arrows in $H$ ) but otherwise unaffected at the level of the AM compared with WT (data not shown). We concluded that a precocious upregulation of atoh1a in the PM of the neurog1 morphants and neurog1 ${ }^{-/-}$embryos consistently precedes the increase in the number of hair cells. These results indicate that, in the WT situation, neurog1 inhibits atohla expression.
To further confirm that the supernumerary PM hair cells found in the morphants indeed derived from progenitors that expressed neurog 1 at early stages, we performed a lineage tracing of the neurog1-positive cells in the ear. Because none of the available neurog1 transgenic lines (Blader et al., 2003; McGraw et al., 2008) faithfully recapitulate early neurog 1 expression within the otic epithelium, we took advantage of the enhanced stability of neurog1 mRNA in neurog1 morphants (Jeong et al., 2006). This allowed us to follow the fate of neurogenic progenitors well after otic epithelial cells would have normally switched off neurog1 expression (Fig. 3I-L). Brn3:mGFP transgenic embryos were injected with MO-neurog1, and the cells expressing neurog1 mRNA were tracked until $48 \mathrm{hpf}$ (when supernumerary differentiated hair cells could be detected in the PM). Indeed, we found cells coexpressing neurog $1 \mathrm{mRNA}$ and the hair cell differentiation marker in the PM (Fig. 3L, higher magnifications in $M-O$ ). To confirm that neurog1-expressing progenitors could only give rise to hair cells in the PM, we analyzed the AM epithelium and never found GFP-positive cells expressing neurog1 mRNA (Fig. $3 K$, see exclusion of pink and green staining).

Together, these findings indicate that a subset of the neurons and hair cells of the PM share a common progenitor expressing neurog1, which is able to generate both cell types. In contrast, sensory neurons and hair cells of the AM might originate from distinct progenitor pools, which have already been segregated at the onset of neurog1 expression.

\section{The PM contains a pool of \\ bipotent progenitors}

Our next aim was to confirm that the posteromedial otic region contains common bipotent progenitors from which neuronal and sensory cell fates can be specified. For this purpose, we performed lineagetracing analysis after single-cell labeling of otic progenitors using Eos photoconvertible protein (Figs. 4, 5). Embryos were injected at the 8- to 32-cell stage with $n l s-m E o s$ and screened for EosGpositive cells in the otic epithelium, and single cells were photoconverted to EosR at distinct positions along the different axes of the otic vesicle (the time of photoconversion was chosen according to the onset of proneural gene expression for neurons and hair cells; Fig. 1). Embryos were allowed to develop until 48 hpf, when the fate of the photoconverted cell progeny was assessed by both its position (in the SAG for neurons and in the sensory patches for hair cells) and the use of different transgenic lines to visualize specifically the different fates: hair cells (Brn3c:mGFP) or sensory neurons (Isl3:GFP).

In a first set of experiments, single-cell photoconversions were performed at stages between 17 and $22 \operatorname{hpf}(n=12$ in the anterior 
half and $n=16$ in the posterior half of the otic vesicle). At these stages, the only proneural gene broadly expressed in otic epithelial cells is neurog1. As expected, in most of the cases, a single cell photoconverted in the anterior and ventral aspect of the otic vesicle gave rise to neurons found in the SAG at $48 \mathrm{hpf}$ (Fig. $4 B-B^{\prime \prime}$; Isl3:GFP line, $n=6$ of 12). When several cells were simultaneously photoconverted in this territory, the derivatives were neurons, and no red hair cells were found in the otic epithelium (data not shown).

In fewer cases, photoconversion of a single cell performed in the anterior region of the otic vesicle resulted in red derivatives in the $\mathrm{AM}$ epithelium that were identified as hair cells (Fig. $4 C-C^{\prime \prime}$; Brn3c: mGFP line, $n=2$ of 12), indicating that, at these early stages, precursors for neurons and hair cells in the anterior half of the ear were already committed to a specific fate. The low occurrence for the hair cell type in the derivatives is most probably attributable to the bias of our study. Indeed, we mainly focused the lineage tracing on the medial aspect of the vesicle to target the putative common neurosensory progenitors. The remaining single-cell labelings in the anterior region ( $n=4$ of 12$)$ resulted in nonsensory/non-neural (NS/ $\mathrm{NN}$ ) derivatives, because they were all found outside of the sensory patches and SAG (data not shown).

In contrast to the results obtained for the anterior half of the otic vesicle, early photoconversion of single epithelial progenitors located in its posterior half (Fig.

5 ) gave three different outcomes: (1) photoconversion of single ventral progenitors gave derivatives in the SAG (Fig. $5 A-A^{\prime \prime} ; n=$ 6 of 16), (2) photoconversion of cells located very posterior and medial consistently gave red hair cells exclusively located in the PM (Fig. $5 B-B^{\prime \prime} ; n=6$ of 16), and (3) lineage tracing of single progenitors located in the medial region of the posterior otic territory (intermediate position between the two previously described) resulted in red derivatives within the SAG and in red hair cells in the PM (Fig. 5C-C'; $n=2$ of 16). The other cell labelings ( $n=2$ of 16) had only NS/NN descendents (data not shown).

Photoconversions performed at later stages (24-26 hpf) after atoh1a has expanded in the AM showed similar results supporting the idea that the sensory and neuronal lineages are unrelated in the anterior part of the ear, whereas a given population of progenitors located in a restricted region of the posterior and medial epithelium was able to give rise to neurons and hair cells (data not shown).

Overall, these results demonstrate that the otic epithelium contains three types of neurosensory progenitors: (1) neuronal precursors that give only neurons, (2) sensory precursors giving rise to hair cells, and (3) a small pool of common progenitors able to generate hair cells and neurons, located in the posteromedial domain of the otic epithelium. The timing for commitment of the distinct progenitor populations to a given cell fate is also different between AM and PM. Finally, these results suggest that neurog1- expressing progenitors of the AM form a first clonal compartment from which only neurons will be generated and then another set of progenitors will be defined to give AM hair cells. In contrast, neurog1 progenitors of the PM are not restricted to the neuronal fate and behave as true bipotent progenitors.

\section{neuroD1 requirement for hair cell production in the $\mathrm{PM}$}

Next, we wanted to unveil the molecular mechanism underlying hair cell production during neurog1 downregulation. Neurosensory progenitors with a dual potential have been characterized in a time and place that fits with a possible expression of neuroD1. Although this bHLH factor has been involved primarily in otic neuronal survival and differentiation (Liu et al., 2000; Jahan et al., 2010a), some evidence also suggested a role for neuroD1 in sensory development (Matei et al., 2005; Jahan et al., 2010b). These data led us to address whether neuroD1 could play a role in hair cell fate.

To answer this question, our first approach was to analyze the expression of neuroD1 in the otic epithelium of neurog1 morphants and neurog1 $1^{-/}$mutants (Fig. 6). The expression of neuroD1 and neuroD4 in the otic epithelium of the morphants was abolished already at $24 \mathrm{hpf}$ (Fig. 6A-D), consistent with the previously described role of neurog1 in early activation of neuroD1 and neuroD4 in the differentiating neuronal population (Ma et al., 1998; Andermann et al., 2002; Madelaine et al., 2011). 

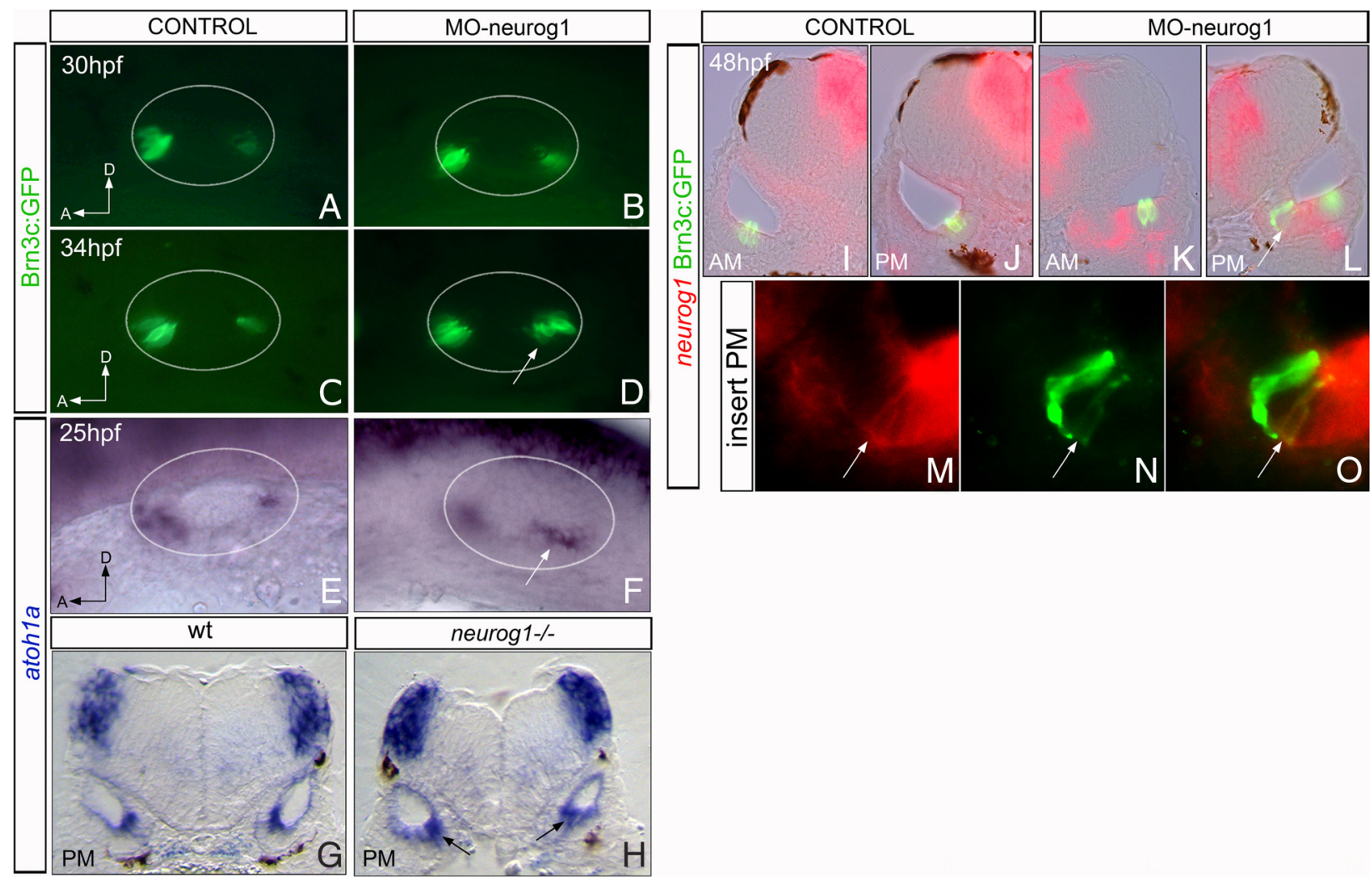

Figure 3. neurog1 negatively controls hair cell fate in the PM through atoh1a inhibition. Hair cell production $(\boldsymbol{A}-\boldsymbol{D})$ and atoh 1a expression $(\boldsymbol{E}-\boldsymbol{H})$ in control $(\boldsymbol{A}, \boldsymbol{C}, \boldsymbol{E}), \mathbf{M 0}-$ neurog1 $(\boldsymbol{B}, \boldsymbol{D}, \boldsymbol{F})$, WT $(\boldsymbol{G})$, and neurog $1^{-1-}(\boldsymbol{H})$ embryos. $\boldsymbol{E}$ and $\boldsymbol{F}$ are lateral views focusing on the PM. Arrows in $\boldsymbol{D}$ and $\boldsymbol{F}$ point to supernumerary hair cells in the PM at 34 hpf and to precocious atoh $7 a$ expression in the PM of M0-neurog1 at $25 \mathrm{hpf}$, respectively. Arrow in $\boldsymbol{H}$ points to an enlargement of the PM atoh $1 a$-expressing domain in neurog $1^{-1-}$. White circles indicate the contour of the otic vesicle. $\boldsymbol{A}-\boldsymbol{F}$, Lateral views with anterior to the left and dorsal to the top. $\mathbf{G}, \boldsymbol{H}$, Transverse sections through the PM. I-L, Transverse sections of tg[Brn3:mGFP] embryos after fluorescent in situ hybridization for neurog 1 (red), followed by immunostaining with anti-GFP (green) to detect hair cells at $48 \mathrm{hpf} . \boldsymbol{I}, \boldsymbol{J}$, Control embryos; $\boldsymbol{K}, \boldsymbol{L}$, neurog1-morphant embryos. Note that, in the ear of control embryos, neurog 1 expression has been already turned off at this stage $(I, J)$. On the contrary, in morphant embryos, neurog $1 \mathrm{mRNA}$ is still detectable, but no hair cells expressing neurog 1 were found at the level of the AM $(\boldsymbol{K})$. A cell in the PM expressing neurog 1 and displaying hair cell characters is shown in $\boldsymbol{L}$ (arrow; and arrows in $\boldsymbol{M}-\mathbf{0})$. $\boldsymbol{M}-\mathbf{0}$, Inserts from the PM $(\boldsymbol{L})$, showing the red $(\boldsymbol{M})$ and green $(\boldsymbol{N})$ channels and the merge $(\boldsymbol{O})$. A, Anterior; D, dorsal.

However, expression analysis performed in morphants at 30 hpf showed that the expression of neuroD1 and neuroD4 had recovered in the posterior part of the otic epithelium (Fig. 6E, F and data not shown), suggesting that, although the early expression of neuroD1 and neuroD4 required neurog1, the late neuroD1 and neuroD4 expression did not. In situ hybridization for neuroD1 in neurog1 ${ }^{-1-}$ embryos was not conclusive, suggesting that either at least part of the neuroD1 expression detected in the morphants could reflect a progressive loss of the efficiency of the MO-neurog1 or the level of neuroD1 expression in the mutants was too low to be detected with this technique. In line with the latter possibility, neuroD1 protein was detected in the posterior and medial region of the otic vesicle in neurog $1^{-1-}$ embryos, as found in WT embryos (Fig. $6 \mathrm{H}, \mathrm{J}$ ), whereas no staining was obtained in the SAG (Fig. 6G,I).

These results strongly suggest that there is a late wave of neuroD1 expression in the otic epithelium independent of neurog1, which could be responsible for the production of supernumerary hair cells during neurog1 loss of function.

Then, we examined whether neuroD1 was required for hair cell formation. For this purpose, we performed loss-of-function experiments by injecting MO-neuroD1 in $\operatorname{tg}[\mathrm{Brn} 3 \mathrm{c}: \mathrm{mGFP}]$ embryos. neuroD1 morphants displayed a consistent reduction in the number of hair cells of the PM at $56 \mathrm{hpf}$ and $3 \mathrm{dpf}$ with no differences in the number of hair cells in the AM (Fig. 7A-E; AM: control, $27.2 \pm 3.2$ cells, $n=10$; MO-neuroD1, $26.7 \pm 2.6$ cells, $n=21$; PM: control,
$31.6 \pm 4.1$ cells, $n=10$; MO-neuroD, $24.8 \pm 3.2$ cells, $n=21 ; p<$ 0.005). This suggested that a specific population of progenitors of the PM could not undergo hair cell specification in the absence of neuroD1. Interestingly, the knockdown of neuroD1 appeared to reduce hair cell production only in the anterior domain of the PM, the same region that displayed an opposite phenotype in the neurogl morphant and neurog1 ${ }^{-1-}$ embryos. Thus, these data suggest that neuroD1 is required for proper hair cell development in the PM.

However, to demonstrate that the late wave of neuroD1 was responsible for the supernumerary hair cell production during neurog-1 loss of function, rescue experiments were needed. Thus, if this hypothesis was correct, we expected that downregulation of neuroD1 in $\operatorname{tg}[\mathrm{Brn} 3 \mathrm{c}: \mathrm{mGFP}]$ neurog1 $1^{-/-}$embryos would rescue the phenotype of supernumerary PM hair cells. As shown in Figure $7 F-H$, embryos lacking both neurog 1 and neuroD1 function displayed a number of hair cells in the PM comparable with WT embryos, with no effects in the number of hair cells in the AM. The ratio AM/PM was used to better analyze the rescue effect of MO-neuroD1 (Table 1). The number of hair cells in the AM and $\mathrm{PM}$ was similar at $48 \mathrm{hpf}$ in WT embryos (Table 1, see AM/PM = 1.13; Fig. 7F; see also quantifications in Fig. $2 I, K$ ), whereas the loss of function of neurog1 resulted in an increase of hair cell numbers in the PM (Table 1, see AM/PM = 0.79; Fig. $7 G$; see also quantifications in Fig. $2 \mathrm{~K}$ ). In contrast, the morphants for neuroD1 displayed the opposite effect, namely a decrease in the number of hair cells in the PM (Table 1, see AM/PM = 1.45; Fig. 7E). 

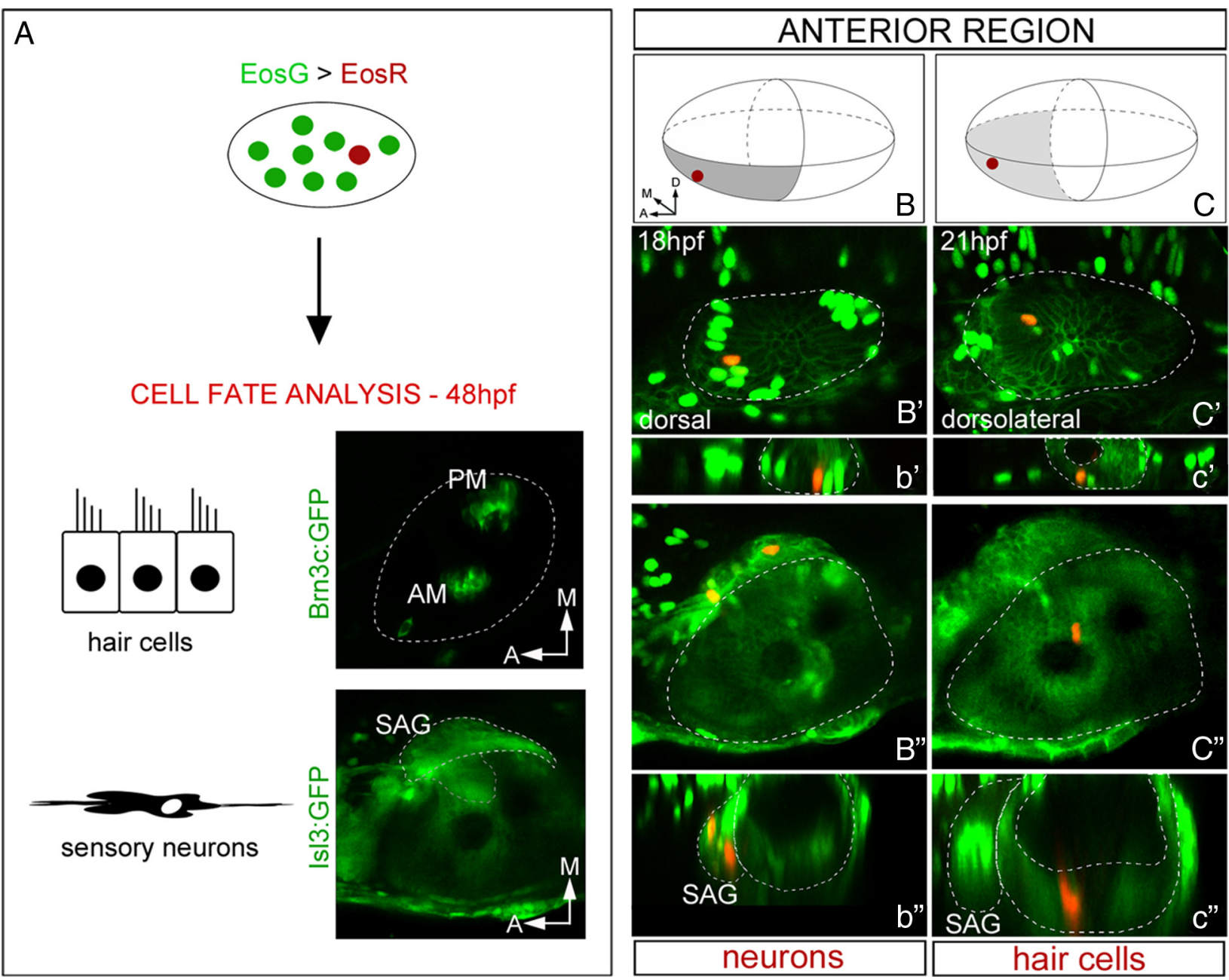

Figure 4. Single-cell tracing of anterior otic neurosensory progenitors. $\boldsymbol{A}$, Scheme depicting the logic of the single-cell tracing experiment: embryos are injected at 8 - to 32 -cell stage with $n / s-$ eos, incubated until $18-20 \mathrm{hpf}$, and screened for EosG-positive cells. The desired single EosG cell is photoconverted to EosR, and embryos are allowed to develop until $48 \mathrm{hpf}$ to analyze the fate of the progeny of the photoconverted cell using specific transgenic lines. $\boldsymbol{B}, \boldsymbol{C}, 3 \mathrm{D}$-like otic vesicle schemes indicating the position of the photoconverted cell displayed in $\boldsymbol{B}^{\prime}$ and $\boldsymbol{C}^{\prime}$. Axes are indicated in $\boldsymbol{B}$, the region of the vesicle in which the cell is located is colored in gray (dark gray indicates lateral and light gray medial). $\boldsymbol{B}^{\prime}, \boldsymbol{C}^{\prime}$, Single-photoconverted cell in the otic epithelium at the given time. Orientation of the embryos is indicated in the picture with anterior always to the left. $\boldsymbol{b}^{\prime}, \boldsymbol{C}^{\prime}$, yz confocal cross-sections of $\boldsymbol{B}^{\prime}$ and $\boldsymbol{C}^{\prime}$ to verify that indeed only a single cell was hit. $\boldsymbol{B}^{\prime \prime}, \boldsymbol{C}^{\prime \prime}$, Cell fate analyses at $48 \mathrm{hpf}$ of photoconverted cells shown in $\boldsymbol{B}^{\prime}$ and $\boldsymbol{C}^{\prime}$ using either Brn3c:mGFP or IsI3:GFP transgenic lines, as well as the position in the sensory patch or in the SAG. Dorsal views with anterior to the left. $\boldsymbol{b}^{\prime \prime}, \boldsymbol{c}^{\prime \prime}$, yz confocal cross-sections of $\boldsymbol{B}^{\prime \prime}$ and $\boldsymbol{C}^{\prime \prime}$ to verify the fate of the cell derivatives by their position in the epithelium or in the SAG. A, Anterior; D, dorsal; M, medial.

However, when neuroD1 function was abrogated in the neurog $1^{-/-}$embryos, the phenotype was rescued in $30 \%$ of the morpholino-injected embryos (Table 1, see AM/PM = 1; Fig. $7 H$ ). To avoid the possible off-target effects of morpholino injections mediated by activation of p53 pathway (Gerety and Wilkinson, 2011), we inhibited p53-associated apoptosis coinjecting MO-neuroD1 and MO-p53. Thus, these experiments demonstrate that neuroD1 is required for the generation of supernumerary hair cells in the absence of neurogl function.

Last, to determine whether neuroD1 was sufficient to confer hair cell fate, we performed gain-of-function experiments. We coinjected neuroD1 and H2B-mcherry mRNAs to track the cells that expressed ectopic neuroD1 (Fig. 7I-M). The missexpression strategy was validated by the ability of DsRed-labeled cells to induce ectopic neurons when injected in Isl3:GFP embryos at the 1 - to 2-cell stage (Fig. 7I, arrows), recapitulating the induction of ectopic neuronal markers obtained by neuroD1 overexpression (Ochocinska and Hitchcock, 2009). No effects on neurons or hair cells were observed when $H 2 B$-mcherry alone was injected (data not shown). As expected from the well-described role of neuroD1 in neuronal differentiation, most of the cells expressing exogenous neuroD1 were found in the SAG according to DsRed staining (Fig. 7J). Because injection of neuroD1 mRNA at such early stages often resulted in major embryo deformations, to overcome this problem, we injected Brn3c:mGFP embryos at the 16-cell stage to further analyze the role of neuroD1 in hair cell fate acquisition. The vast majority of cells expressing exogenous neuroD1 were found in the SAG and the neural tube (Fig. $7 K$ ), whereas very few of them were located in the otic epithelium (Fig. $7 K-M$ ). No hair cells containing ectopic neuroD1 were detected within the AM sensory epithelium, although in very rare cases, Brn3c: mGFP-positive cells that incorporated neuroD1 were found extruded from the otic epithelium (see asterisk in red and green cell in Fig. $7 L$ ). In contrast, the PM presented hair cells (green) that expressed exogenous neuroD1 (red) (Fig. $7 M$ ), although these cells were never detected at ectopic positions.

Thus, our gain-of-function studies suggest that neuroD1 is not sufficient to induce hair cell fate. However, we cannot exclude that neuroD1 either requires a specific environment and/or partners to drive hair cell fate or it can act only during a very short 


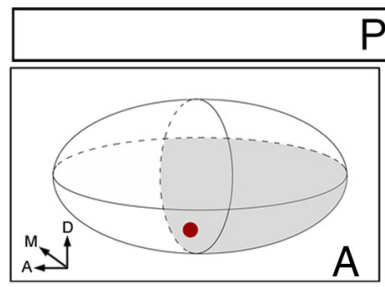

POSTERIOR REGION
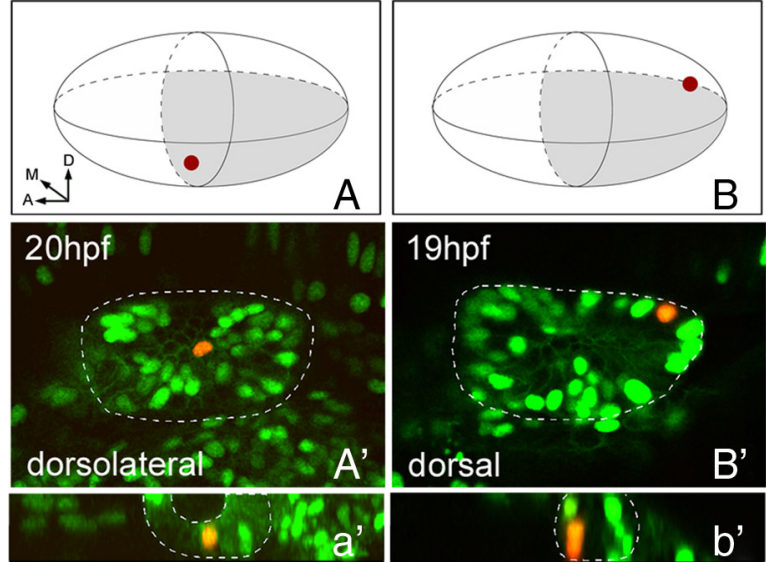

B'
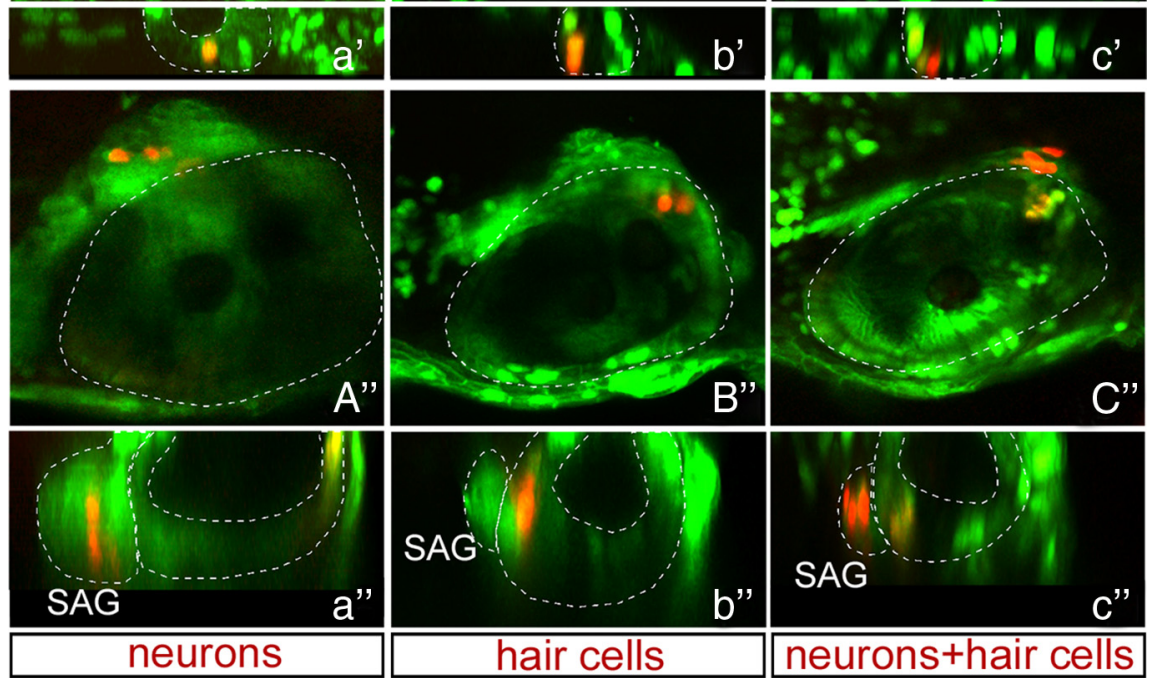

Figure 5. Single-cell tracing of posterior otic neurosensory progenitors. The rationale of the experiment is the same as in Figure $4 A$. $\boldsymbol{A}-\boldsymbol{C}$, 3D-like otic vesicle schemes indicating the positions of the photoconverted cells displayed in $\boldsymbol{A}^{\prime}-\boldsymbol{C}^{\prime}$. Axes are indicated in $\boldsymbol{A}$, and the region of the vesicle in which the cell is located is colored in gray (light gray indicates medial). $\boldsymbol{A}^{\prime}-\boldsymbol{C}^{\prime}$, Singlephotoconverted cell in the otic epithelium at the given time. Orientation of the embryos is indicated in the picture with anterior always to the left. $\boldsymbol{a}^{\prime}-\boldsymbol{c}^{\prime}$, yz confocal cross-sections of $\boldsymbol{A}^{\prime}-\boldsymbol{C}^{\prime}$ to verify that indeed only a single cell was hit. $\boldsymbol{A}^{\prime \prime}-\boldsymbol{C}^{\prime \prime}$, Cell fate analyses at $48 \mathrm{hpf}$ of photoconverted cells shown in $\boldsymbol{A}^{\prime}-\boldsymbol{C}^{\prime}$ using either Brn3c:mGFP or Is|3:GFP transgenic lines, as well as the position in the sensory patch or the SAG. Dorsal views with anterior to the left. $\boldsymbol{a}^{\prime \prime}-\boldsymbol{c}^{\prime \prime}, y z$ confocal cross-sections of $\boldsymbol{A}^{\prime \prime}-\boldsymbol{C}^{\prime \prime}$ to verify the fate of the cell derivatives by their position in the epithelium or the SAG. A, Anterior; D, dorsal; M, medial.

temporal window that has been missed in the experiment. Nonetheless, these results show that cells expressing exogenous neuroD1 cannot be incorporated in the sensory cells of the AM, whereas expression of neuroD1 is compatible with the acquisition of the hair cell fate in the PM.

\section{Discussion}

The otic neurosensory precursors are composed of three different populations defined by the proneural gene combination

Hair cells and neurons are the key cell types for the functions of the inner ear, and they are specified in the otic vesicle in the same way in fish, birds, and mammals. However, there are differences, and one of them is that in the fish neurons and hair cells originate simultaneously from approximately the same regions. Thus, the first hair cells differentiate while neuronal precursors are still delaminating, and hair cells continue to be produced throughout life (Haddon and Lewis, 1996). In an attempt to define the sequential generation of hair cells and neurons of the otic sensory patches, we sought to characterize the neurosensory progenitor populations and the role of proneural genes in the coordination of their simultaneous production. Expression analyses of atohla and neuroD1 show that they are expressed in segregated territories of the anterior region of the otic vesicle, whereas both genes overlap in the posterior otic epithelium. This suggests that a subset of sensory neurons and hair cells of the PM derives from a common progenitor field.

By lineage tracing experiments, we revealed three pools of progenitors with different potentialities and proneural requirements. First, we show that most of hair cells originate from unipotent progenitors located in the anterior or most posterior poles of the otic epithelium and that the majority of the neuronal progenitors generate only neurons. Loss of function of neurog 1 confirm that the neurons and sensory elements of the AM arise from segregated precursor populations, which commit very early to their alternative fates. Indeed, this is consistent with previous work showing that neurog1/neuroD1 are essential for neuron development (Andermann et al., 2002) and atoh1 for hair cell specification (Millimaki et al., 2007). Because neurog1 expression precedes atoh $1 a$, there is the possibility of an early sequential determination for the neuronal fate first and then to the sensory fate, as has been shown in the preplacodal region of the lateral line (Mizoguchi et al., 2011). Although recent studies suggested a crucial role for Sixl in balancing the numbers of hair cells and neurons in the AM, this might happen after precursors are committed to the given fate, probably fine-tuning hair cell proliferation and neuronal death (Bricaud and Collazo, 2011).

Second, we identified a population of bipotent progenitors located in the posteromedial epithelium that generate sensory cells and neurons from clonally related cells. We show that a subset of the neurogenic precursors can shift to the hair cell fate; interestingly, they are located in the ant-PM, which corresponds to the future saccular macula (Haddon and Lewis, 1996). Our functional studies show that, in the bipotent progenitors, neurog1 inhibits atohla, whereas neuroD1 would be the key player for hair cell fate specification. The specific role of neuroD1 in these precursors could be explained by the precise allocation of this cell population to the posteromedial region of the otic vesicle, which could provide them a specific environment and/or neuroD1 partners, to allow neuroD1 to play this function. In line with this, we showed in a previous study that the establishment of the otic posteromedial expression domain of proneural genes depends on hedgehog signaling (Sapède and Pujades, 2010).

A potential difference during neurosensory development between mouse and zebrafish is the proneural function of atoh1 genes (Millimaki et al., 2007). In particular, the early atoh1b expression in the preotic placode could suggest that atoh $1 b$ might be the early proneural gene defining the bipotent progenitor pop- 


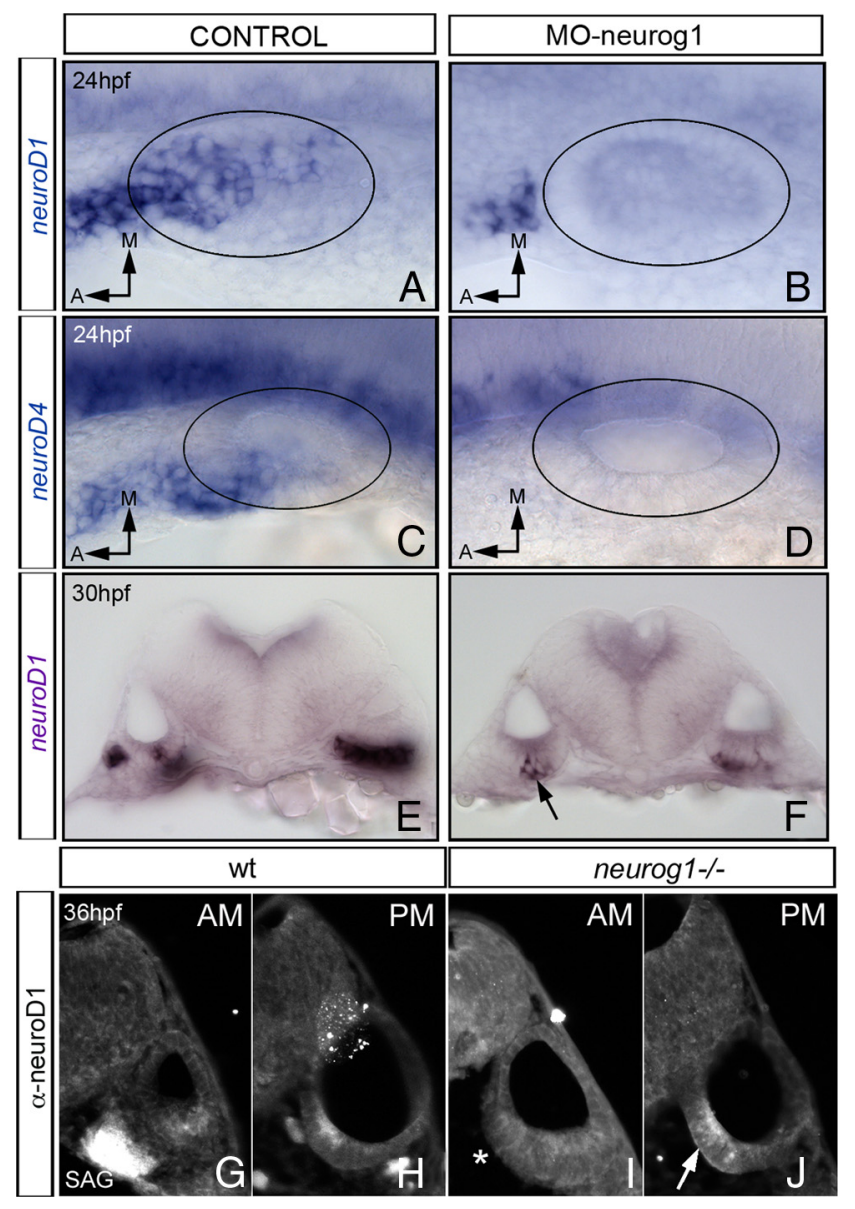

Figure 6. Late neuroD1 expression in the PM is independent of neurog1. In situ hybridization for neuroD1 $(\boldsymbol{A}, \boldsymbol{B}$ and $\boldsymbol{E}, \boldsymbol{F})$ and neuroD4 $(\boldsymbol{C}, \boldsymbol{D})$ in control embryos $(\boldsymbol{A}, \boldsymbol{C}, \boldsymbol{E})$ and morphant embryos for neurog1 $(\boldsymbol{B}, \boldsymbol{D}, \boldsymbol{F})$. Although no expression of neuroD1 or neuroD4 is observed in the otic epithelium of M0-neurog1 at $24 \mathrm{hpf}(\boldsymbol{A}-\boldsymbol{D})$, few cells in the posterior otic epithelium express neuroD1 at $30 \mathrm{hpf}(\boldsymbol{E}, \boldsymbol{F}$, see arrow in $\boldsymbol{F})$. Transverse sections through the $\operatorname{AM}(\boldsymbol{G}, \boldsymbol{I})$ and the PM $(\boldsymbol{H}, \boldsymbol{J})$ ofWT $(\boldsymbol{G}, \boldsymbol{H})$ and neurog $1^{-/-}(\boldsymbol{I}, \boldsymbol{J})$ embryos immunostained with anti-neuroD1. Note the expression of neuroD in the $\operatorname{SAG}(\boldsymbol{G})$ and in the posterior domain of the otic epithelium $(\boldsymbol{H})$ in WT embryos. As expected, in neurog $1^{-/-}$embryos, neuroD1 is not detected in the SAG ( $I$, asterisk); however, neuroD1 is still present in the posteromedial domain of the otic epithelium ( $\boldsymbol{J}$, see arrow). A-D, Dorsal views with anterior to the left. $\boldsymbol{E}-\boldsymbol{J}$, Transverse sections. Black circles indicate the contour of the otic vesicle. A, Anterior; M, medial.

ulation, as neurog1 does in mice. However, this seems unlikely for three reasons: (1) atoh $1 b$ is already downregulated at the onset of neurog1 (Millimaki et al., 2007), (2) our results show that the proneural genes overlapping in the bipotent progenitor territory are neuroD1 and atohla (not atoh1b), and (3) the progenitor cells able to change their fate to hair cells are neurog1-positive cells. Therefore, it seems that, although there are some differences in the timing of neuronal and hair cell specification in distinct species, the different progenitor pools and the neurosensory specification mechanism are conserved.

\section{neuroD1 is required for hair cell fate in the bipotent progenitors}

We have identified a pool of common progenitors for neurons and hair cells. The small size of the cell clones obtained by photoconversion suggests that these cells could commit to a given fate only in the last rounds of cell proliferation and possibly maintain a cell population with self-renewal capacity within the otic epithelium. It would be plausible that this capacity gives an advantage to the fish in the case of cell loss, because regeneration of neurosensory cells could be quickly accomplished. It would be interesting to see whether other species with regeneration properties, such as the chick, contain a similar population of bipotent progenitors.

Our functional experiments show that neuroD1 is required for hair cell specification. neuroD1 has been primarily involved in sensory neuron differentiation and survival (Kim et al., 2001; Jahan et al., 2010a). Nevertheless, there is evidence suggesting a role for neuroD1 in hair cell development: it is detected in hair cells at later stages of inner ear development and suppresses premature hair cell differentiation (Jahan et al., 2010b), mutant embryos for neurog1 display ectopic neuroD1-positive hair cells (Matei et al., 2005), and finally, neuroD1 has been directly involved in hair cell differentiation in the posterior lateral line (Sarrazin et al., 2006). In mice, neuroD1 is regulated by both neurog1 and atoh1 and provides a negative feedback for either gene (Jahan et al., 2010b; Pan et al., 2012a). Our results show that late neuroD1 expression in the posterior otic epithelium drives the common neurosensory progenitor to the hair cell program, independently of neurog1. Thus, most probably, atoh1a activates neuroD1 in that given territory as it happens in the posterior lateral line (Sarrazin et al., 2006) and in the inner ear in mice (Pan et al., 2012a). Although neuroD genes have been identified as direct targets of neurog1 during neuronal specification (Ma et al., 1998; Andermann et al., 2002), there are examples in which they are not targets. neuroD4 in the neural tube (Park et al., 2003) and in the olfactory system (Madelaine et al., 2011) can act independently of neurog1, which would resemble what we observe with neuroD1 and neuroD4 in the otic epithelium. In our system, the expression of atoh1a and neuroD1 (independent of neurog1) would prime the progenitor cells to orient them toward the hair cell fate. This could explain why the ectopic expression of atoh 1 a mRNA is not sufficient to generate ectopic hair cells (Millimaki et al., 2007), most probably because they concomitantly need the presence of neuroD1.

Although required for hair cell specification, neuroD1 is not sufficient to confer hair cell fate. These results are in line with recent analysis performed in mice, in which in the absence of atoh1, neither neurog1 nor neuroD1 can fully rescue hair cell differentiation (Jahan et al., 2012).

\section{Making neurosensory cells from a common progenitor: importance for regeneration therapies}

In mammals, hair cells and auditory neurons are only produced during the embryonic stages, and the capacity to replace damaged sensory cells is lost soon after birth, making deafness irreversible. Therefore, a better understanding of the molecular mechanisms determining the fate of these cell types from early progenitors is a prerequisite for the elaboration of new efficient therapeutic strategies (for review, see Pan et al., 2012b). There is only limited evidence for the presence of neurosensory stem cells in the vestibular organs of adult mice (Li et al., 2003), and the adult cochlea does not seem to harbor an equivalent population beyond the early postnatal stages (Oshima et al., 2007). Our data demonstrate that a pool of otic neuronal precursors can also form hair cells, which could allow the study of how a neuronal stem cell is transformed in both neurons and hair cells. This might also give important insights for the production of hair cells in vitro by ectopic expression of atoh $1 a$ in neuronal progenitors that already express neuroD1, to use them as an exogenous source for hair cell replacement. Interestingly, large pools of more accessible 

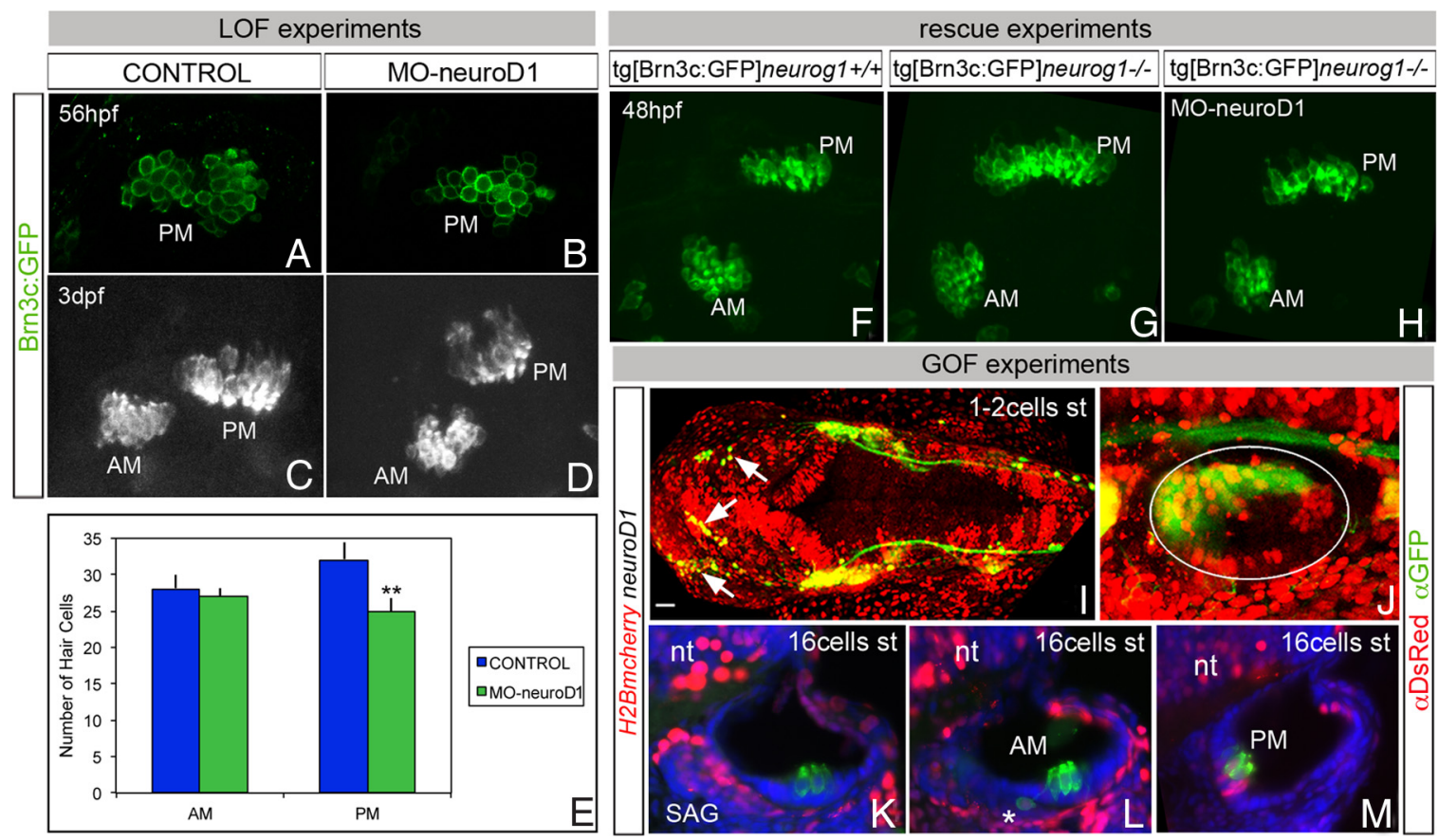

Figure 7. neuroD1 is necessary but not sufficient for hair cell production in the PM. $\boldsymbol{A}-\boldsymbol{D}$, Loss-of-function (LOF) experiments: control $(\boldsymbol{A}, \boldsymbol{C})$ and neuroD1-morphant ( $\boldsymbol{B}, \boldsymbol{D})$ embry0s at 56 hpf $(\boldsymbol{A}$, $\boldsymbol{B})$ and $3 \mathrm{dpf}(\boldsymbol{C}, \boldsymbol{D})$. Note defective hair cell production in the PM of the morphants, with no effects in the AM $(\boldsymbol{C}, \boldsymbol{D})$. $\boldsymbol{E}$, Quantification of hair cells in AM and PM of control and morphant embryos at $56 \mathrm{hpf}$, confirming the restriction of hair cell loss to the PM. ${ }^{* *} p<0.005$. $\boldsymbol{F}-\boldsymbol{H}$, Rescue experiments showing dorsolateral views of WT, neurog $1^{-1-}$, and neurog $1^{-1-}$ M0-neuroD1-injected embryos in the $\operatorname{tg}[\mathrm{Brn} 3 \mathrm{c}: \mathrm{mGFP}]$ background at $48 \mathrm{hpf}$. Note that the knockdown of neuroD1 restores the size of the PM in neurog ${ }^{-/-}$embryos (compare $\left.\mathbf{G}, \boldsymbol{H}\right)$. I-M, Gain-of-function (GOF) experiments for neuroD1 in IsI3:GFP $(\boldsymbol{I}, \boldsymbol{J})$ or Brn3c:mGFP $(\boldsymbol{K}-\boldsymbol{M})$ transgenic embryos. neuroD1 and H2B-mcherry mRNAs were coinjected in 1- to 2-cell stage $(\boldsymbol{I}, \boldsymbol{J})$ or 16 -cell stage $(\boldsymbol{K}-\boldsymbol{M})$ embryos. Double immunostainings with anti-DsRed (red) and anti-GFP (green) were performed to identify cells expressing exogenous neuroD1 (red) and hair cells or neurons (green). Ectopic neurons were found after neuroD injections ( $\boldsymbol{I}$, arrows). Many cells containing ectopic neuroD1 were found in the SAG and the neural tube $(\boldsymbol{J}, \boldsymbol{K})$, and no red cells were found in the AM $(\boldsymbol{L})$. Although neuroD1-expressing cells found in the PM display hair cell properties $(\boldsymbol{M})$, ectopic neuroD1 is not sufficient to induce ectopic hair cell specification. Blue color in $\boldsymbol{K}-\boldsymbol{M}$ corresponds to the cell nuclei stained with DAPI. Lateral $(\boldsymbol{A}, \boldsymbol{B}, \boldsymbol{J})$ and dorsolateral $(\boldsymbol{C}, \boldsymbol{D}$ and $\boldsymbol{F}-\boldsymbol{H})$ views with anterior to the left and dorsal to the top. $\boldsymbol{I}$, Dorsal view with anterior to the left. $\boldsymbol{K}-\boldsymbol{M}$, Transverse sections at different anteroposterior levels (with $\boldsymbol{K}$ being anterior and $\boldsymbol{M}$ posterior). nt, Neural tube.

Table 1. Loss of neuroD1 function in the neurog $1^{-/-}$mutants is able to rescue the hair cell defects

\begin{tabular}{lclll}
\hline & AM & PM & Ratio AM/PM & $n$ \\
\hline WT controls & $19.2 \pm 3.1$ & $17.1 \pm 2.6$ & 1.13 & 15 \\
neurog1 $^{-/}$controls & $21.8 \pm 1.8$ & $27.5 \pm 3$ & 0.79 & 16 \\
WT M0-neuroD1 $^{-17.9 \pm 1.7}$ & $12.6 \pm 1.96$ & 1.45 & 20 of 33 \\
neurog1 $^{-1}$ M0-neuroD1 & $19 \pm 4$ & $19.5 \pm 5$ & 1 & 8 of 26 \\
\hline
\end{tabular}

Quantification of the AM and PM hair cells at 48 hpf in different embryos: $\operatorname{tg}[\mathrm{Brn} 3 \mathrm{c}: G F P]$ neurog $1^{+/+}, \operatorname{tg}[\mathrm{Brn} 3 \mathrm{C}$ GFP] neurog $1^{-/-}$, and tg[Brn3c:GFP]neurog ${ }^{-/-}$coinjected with M0-neuroD1 and M0-p53. Note that the phenotype displayed by $\operatorname{tg}[\mathrm{Brn} 3 \mathrm{CGFP}]$ neurog $1^{-1-}$ in the PM (supernumerary hair cells) is rescued in $30 \%$ (8 of 26) of the embryos injected with M0-neuroD1. See that AM/PM $=1$ in $\operatorname{tg}\left[\right.$ Brn3c:GFP]neurog $1^{-/-}$M0-neuroD1injected embryos (similar to WT AM/PM $=1.13$ ) compared with the non-injected ones (AM/PM $=0.79)$.

neuroD1-expressing neuronal progenitors have been found recently in the adult olfactory epithelium (Packard et al., 2011).

\section{References}

Andermann P, Ungos J, Raible DW (2002) Neurogenin1 defines zebrafish cranial sensory ganglia precursors. Dev Biol 251:45-58. CrossRef Medline Bermingham NA, Hassan BA, Price SD, Vollrath MA, Ben-Arie N, Eatock RA, Bellen HJ, Lysakowski A, Zoghbi HY (1999) Math1: an essential gene for the generation of inner ear hair cells. Science 284:1837-1841. CrossRef Medline

Bermingham-McDonogh O, Rubel EW (2003) Hair cell regeneration: winging our way towards a sound future. Curr Opin Neurobiol 13:119126. CrossRef Medline

Blader P, Fischer N, Gradwohl G, Guillemot F, Strähle U (1997) The activity of neurogenin 1 is controlled by local cues in the zebrafish embryo. Development 124:4557-4569. Medline

Blader P, Plessy C, Strähle U (2003) Multiple regulatory elements with spatially and temporally distinct activities control neurogenin 1 expression in primary neurons of the zebrafish embryo. Mech Dev 120:211-218. CrossRef Medline

Brend T, Holley SA (2009) Zebrafish whole mount high-resolution double fluorescent in situ hybridization. J Vis Exp pii:1229. CrossRef

Bricaud O, Collazo A (2011) Balancing cell numbers during organogenesis: Sixla differentially affects neurons and sensory hair cells in the inner ear. Dev Biol 357:191-201. CrossRef Medline

Cornell RA, Eisen JS (2002) Delta/Notch signaling promotes formation of zebrafish neural crest by repressing Neurogenin 1 function. Development 129:2639-2648. Medline

Corwin JT, Cotanche DA (1988) Regeneration of sensory hair cells after acoustic trauma. Science 240:1772-1774. CrossRef Medline

Curran K, Lister JA, Kunkel GR, Prendergast A, Parichy DM, Raible DW (2010) Interplay between Foxd3 and Mitf regulates cell fate plasticity in the zebrafish neural crest. Dev Biol 344:107-118. CrossRef Medline

Fritzsch B, Beisel KW, Hansen LA (2006) The molecular basis of neurosensory cell formation in ear development: a blueprint for hair cell and sensory neuron regeneration? Bioessays 28:1181-1193. CrossRef Medline

Gerety SS, Wilkinson DG (2011) Morpholino artifacts provide pitfalls and reveal a novel role for pro-apoptotic genes in hindbrain boundary development. Dev Biol 350:279-289. CrossRef Medline

Golling G, Amsterdam A, Sun Z, Antonelli M, Maldonado E, Chen W, Burgess S, Haldi M, Artzt K, Farrington S, Lin SY, Nissen RM, Hopkins N (2002) Insertional mutagenesis in zebrafish rapidly identifies genes essential for early vertebrate development. Nat Genet 31:135-140. CrossRef Medline

Haas P, Gilmour D (2006) Chemokine signaling mediates self-organizing tissue migration in the zebrafish lateral line. Dev Cell 10:673-680. CrossRef Medline

Haddon C, Lewis J (1996) Early ear development in the embryo of the zebrafish, Danio rerio. J Comp Neurol 365:113-128. CrossRef Medline

Haddon C, Jiang YJ, Smithers L, Lewis J (1998) Delta-Notch signalling and 
the patterning of sensory cell differentiation in the zebrafish ear: evidence from the mind bomb mutant. Development 125:4637-4644. Medline

Hauptmann G, Gerster T (1994) Two-color whole-mount in-situ hybridization to vertebrate and Drosophila embryos. Trends Genet 10:266. CrossRef Medline

Itoh M, Chitnis AB (2001) Expression of proneural and neurogenic genes in the zebrafish lateral line primordium correlates with selection of hair cell fate in neuromasts. Mech Dev 102:263-266. CrossRef Medline

Jahan I, Kersigo J, Pan N, Fritzsch B (2010a) Neurod1 regulates survival and formation of connections in mouse ear and brain. Cell Tissue Res 341:95110. CrossRef Medline

Jahan I, Pan N, Kersigo J, Fritzsch B (2010b) Neurod1 suppresses hair cell differentiation in ear ganglia and regulates hair cell subtype development in the cochlea. PLoS One 5:e11661. CrossRef Medline

Jahan I, Pan N, Kersigo J, Calisto LE, Morris KA, Kopecky B, Duncan JS, Beisel KW, Fritzsch B (2012) Expression of Neurogl instead of Atohl can partially rescue organ of Corti cell survival. PLoS One 7:e30853. CrossRef Medline

Jeong JY, Einhorn Z, Mercurio S, Lee S, Lau B, Mione M, Wilson SW, Guo S (2006) Neurogenin 1 is a determinant of zebrafish basal forebrain dopaminergic neurons and is regulated by the conserved zinc-finger protein Tof/Fezl. Proc Natl Acad Sci U S A 103:5143-5148. CrossRef Medline

Kani S, Bae YK, Shimizu T, Tanabe K, Satou C, Parsons MJ, Scott E, Higashijima S, Hibi M (2010) Proneural gene-linked neurogenesis in zebrafish cerebellum. Dev Biol 343:1-17. CrossRef Medline

Kim WY, Fritzsch B, Serls A, Bakel LA, Huang EJ, Reichardt LF, Barth DS, Lee JE (2001) NeuroD-null mice are deaf due to a severe loss of the inner ear sensory neurons during development. Development 128:417-426. Medline

Langheinrich U, Hennen E, Stott G, Vacun G (2002) Zebrafish as a model organism for the identification and characterization of drugs and genes affecting p53 signaling, Curr Biol 12:2023-2028. CrossRef

Li H, Liu H, Heller S (2003) Pluripotent stem cells from the adult mouse inner ear. Nat Med 9:1293-1299. CrossRef Medline

Liu M, Pereira FA, Price SD, Chu MJ, Shope C, Himes D, Eatock RA, Brownell WE, Lysakowski A, Tsai MJ (2000) Essential role of BETA2/NeuroD1 in development of the vestibular and auditory systems. Genes Dev 14:28392854. CrossRef Medline

Ma Q, Chen Z, del Barco Barrantes I, de la Pompa JL, Anderson DJ (1998) Neurogenin 1 is essential for the determination of neuronal precursors for proximal cranial sensory ganglia. Neuron 20:469-482. CrossRef Medline

Madelaine R, Garric L, Blader P (2011) Partially redundant proneural function reveals the importance of timing during zebrafish olfactory neurogenesis. Development 138:4753-4762. CrossRef Medline

Matei V, Pauley S, Kaing S, Rowitch D, Beisel KW, Morris K, Feng F, Jones K, Lee J, Fritzsch B (2005) Smaller inner ear sensory epithelia in Neurog 1 null mice are related to earlier hair cell cycle exit. Dev Dyn 234:633-650. CrossRef Medline

McGraw HF, Nechiporuk A, Raible DW (2008) Zebrafish dorsal root ganglia neural precursor cells adopt a glial fate in the absence of neurogenin 1. J Neurosci 28):12558-12569. CrossRef

Millimaki BB, Sweet EM, Dhason MS, Riley BB (2007) Zebrafish atoh1 genes: classic proneural activity in the inner ear and regulation by Fgf and Notch. Development 134:295-305. CrossRef Medline
Mizoguchi T, Togawa S, Kawakami K, Itoh M (2011) Neuron and sensory epithelial cell fate is sequentially determined by notch signaling in zebrafish lateral line development. J Neurosci 31:15522-15530. CrossRef Medline

Ochocinska MJ, Hitchcock PF (2009) NeuroD regulates proliferation of photoreceptor progenitors in the retina of the zebrafish. Mech Dev 126: 128-141. CrossRef Medline

Olivier N, Luengo-Oroz MA, Duloquin L, Faure E, Savy T, Veilleux I, Solinas X, Débarre D, Bourgine P, Santos A, Peyriéras N, Beaurepaire E (2010) Cell lineage reconstruction of early zebrafish embryos using label-free nonlinear microscopy. Science 329:967-971. CrossRef Medline

Oshima K, Grimm CM, Corrales CE, Senn P, Martinez Monedero R, Géléoc GS, Edge A, Holt JR, Heller S (2007) Differential distribution of stem cells in the auditory and vestibular organs of the inner ear. J Assoc Res Otolaryngol 8:18-31. CrossRef Medline

Packard A, Giel-Moloney M, Leiter A, Schwob JE (2011) Progenitor cell capacity of NeuroD1-expressing globose basal cells in the mouse olfactory epithelium. J Comp Neurol 519:3580-3596. CrossRef Medline

Pan N, Jahan I, Kersigo J, Duncan JS, Kopecky B, Fritzsch B (2012a) A novel Atoh1 "self-terminating" mouse model reveals the necessity of proper Atoh1 level and duration for hair cell differentiation and viability. PLoS One 7:e30358. CrossRef Medline

Pan N, Kopecky B, Jahan I, Fritzsch B (2012b) Understanding the evolution and development of neurosensory transcription factors of the ear to enhance therapeutic translation. Cell Tissue Res 349:415-432. CrossRef Medline

Park SH, Yeo SY, Yoo KW, Hong SK, Lee S, Rhee M, Chitnis AB, Kim CH (2003) Zath3, a neural basic helix-loop-helix gene, regulates early neurogenesis in the zebrafish. Biochem Biophys Res Commun 308:184-190. CrossRef Medline

Pittman AJ, Law MY, Chien CB (2008) Pathfinding in a large vertebrate axon tract: isotypic interactions guide retinotectal axons at multiple choice points. Development 135:2865-2871. CrossRef Medline

Radosevic M, Robert-Moreno A, Coolen M, Bally-Cuif L, Alsina B (2011) Her9 represses neurogenic fate downstream of Tbx1 and retinoic acid signaling in the inner ear. Development 138:397-408. CrossRef Medline

Raft S, Koundakjian EJ, Quinones H, Jayasena CS, Goodrich LV, Johnson JE, Segil N, Groves AK (2007) Cross-regulation of Ngn1 and Math1 coordinates the production of neurons and sensory hair cells during inner ear development. Development 134:4405-4415. CrossRef Medline

Sapède D, Pujades C (2010) Hedgehog signaling governs the development of otic sensory epithelium and its associated innervation in zebrafish. J Neurosci 30:3612-3623. CrossRef Medline

Sarrazin AF, Villablanca EJ, Nuñez VA, Sandoval PC, Ghysen A, Allende ML (2006) Proneural gene requirement for hair cell differentiation in the zebrafish lateral line. Dev Biol 295:534-545. CrossRef Medline

Satoh T, Fekete DM (2005) Clonal analysis of the relationships between mechanosensory cells and the neurons that innervate them in the chicken ear. Development 132:1687-1697. CrossRef Medline

Xiao T, Roeser T, Staub W, Baier H (2005) A GFP-based genetic screen reveals mutations that disrupt the architecture of the zebrafish retinotectal projection. Development 132:2955-2967. CrossRef Medline 